\title{
Predicting pesticide volatilization from soils ${ }^{\ddagger}$
}

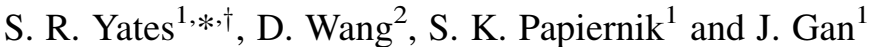 \\ ${ }^{1}$ USDA-ARS, George E. Brown, Jr. Salinity Laboratory, 450 W. Big Springs Rd., Riverside, CA 92507, U.S.A. \\ ${ }^{2}$ Department Soil, Water, and Climate, 1991 Upper Buford Circle, St Paul, MN 55108, U.S.A.
}

\begin{abstract}
SUMMARY
Due to concerns about public health and environmental contamination, there has been great interest in improving our understanding of the processes and mechanisms that affect pesticide emissions from fields. For many situations, predicting pesticide volatilization has been limited to simple situations that often neglect important environmental conditions such as changes in ambient temperature and/or the effect of micrometeorological conditions. Recent research has shown that changes in ambient temperature can strongly affect methyl bromide (Me Br) volatilization under field conditions. Little research has been conducted that couples atmospheric processes to the volatilization of pesticides from soils. A field study was conducted to measure the volatilization of methyl bromide from a 3.5 ha field. Four methods were used to obtain the volatilization rate as a function of time. A one-dimensional numerical model was developed and used to simulate the fate and transport of methyl bromide from the fumigated field. The numerical simulation simultaneously solves water, heat, and solute transport equations including chemical transport in the vapor phase. Three volatilization boundary conditions were used to assess their accuracy in predicting the volatilization rates. The first two boundary conditions follow stagnant boundary layer theory and use no atmospheric information. For these boundary conditions, one assumes isothermal conditions and the other assumes temperature-dependent conditions. The third boundary condition couples soil and atmospheric processes and was found to provide an accurate and credible simulation of the instantaneous volatilization rates compared to a stagnant boundary layer condition. For some information such as cumulative emissions, the simulations for each boundary condition provided similar results. This indicates that simplified methods may be appropriate for obtaining certain information. Published in 2002 by John Wiley \& Sons, Ltd.
\end{abstract}

KEY WORDS: pesticides; volatilization; methyl bromide; emissions; simulation; prediction; mass transfer; surface boundary condition

\section{INTRODUCTION}

During the last 40 to 50 years, methyl bromide $(\mathrm{MeBr})$ has been used to sterilize soils in preparation for planting various high-cash-value fruit and vegetable crops throughout the world. $\mathrm{MeBr}$ is a highly toxic chemical and is very effective in controlling a variety of soil-borne pests, such as nematodes, weeds and fungi. However, it has recently been found to deplete stratospheric ozone and will be phased out by the year 2005. MeBr has been a very important component of agricultural systems in the

*Correspondence to: Dr Scott R. Yates, USDA-ARS, George E. Brown, Jr. Salinity Laboratory, 450 W. Big Springs Rd., Riverside, CA 92507, U.S.A.

${ }^{\dagger}$ E-mail: syates@ussl.ars.usda.gov

¥This article is a US Government work and is in the public domain in the USA.

Published in 2002 by John Wiley \& Sons, Ltd.

Received 27 April 2001

Accepted 15 December 2001 
U.S. and its phase-out is expected to cause severe financial hardship on agricultural producers. Two economic assessments estimate that more than $\$ 1.5$ billion in annual production losses would occur in the United States after the phase-out (NAPIAP, 1993; Ferguson and Padula, 1994).

Methyl bromide use has the potential to cause both environmental and public health problems. There are significant $\mathrm{MeBr}$ emissions from several anthropogenic sources. These include agricultural soil fumigation, which is believed to contribute from 15 to 35 per cent of global sources (Watson et al., 1992). Biomass burning contributes up to $30 \%$ (Mano and Andreae, 1994) and the use of leaded gasoline in automobiles contributes from 1 to 12 per cent (Yvon-Lewis and Butler, 1997). In total, global anthropogenic sources of $\mathrm{MeBr}$ to the atmosphere from fumigation are estimated to be $46 \mathrm{Gg} / \mathrm{yr}$ (Yvon-Lewis and Butler, 1997).

In typical applications, $\mathrm{MeBr}$ is applied to soil using metal shanks that cut into the soil. A nozzle is located at the rear of each shank that emits $\mathrm{MeBr}$ into the soil. The injection depth may vary from approximately $20 \mathrm{~cm}$ to $70 \mathrm{~cm}$. As the tractor moves along the field, a layer of $0.025 \mathrm{~mm}$ (thick) by $3.5 \mathrm{~m}$ (wide) sheet high-density polyethylene (HDPE) plastic film is placed over the soil surface. For each sheet of plastic film, one side is buried in soil and the other is glued to the previous plastic sheet. This creates a series of panels down the field and a continuous plastic cover over the field. $\mathrm{MeBr}$ application rates range from $200 \mathrm{~kg} / \mathrm{ha}$ to $400 \mathrm{~kg} / \mathrm{ha}$ and large fractions ( $24 \%$ to $74 \%$ ) of the applied chemical are lost to the atmosphere (Yagi et al., 1993, 1995; Majewski et al., 1995; Yates et al., 1996b,c; Williams et al., 1999).

Yates et al. $(1996 \mathrm{a}, \mathrm{b}, \mathrm{c})$ conducted a field experiment to investigate the environmental fate and transport of $\mathrm{MeBr}$ after soil fumigation. The experiment was designed to determine the dynamics of $\mathrm{MeBr}$ movement through soil, degradation and cumulative emissions to the atmosphere. $\mathrm{MeBr}$ was applied to a 3.5 ha field, at a depth of $0.25 \mathrm{~m}$ and a rate of $240 \mathrm{~kg} / \mathrm{ha}$. Meteorological measurements of incoming solar radiation, net solar radiation, air temperature gradient, wind speed gradient, wind direction, relative humidity and barometric pressure were obtained, on site, at $10 \mathrm{~min}$ intervals during the experiment. Soil heat flux measurements were taken at 0.05 and $0.1 \mathrm{~m}$ below the soil surface and soil temperature was measured at 0.05-, 0.10-, 0.15-, 0.20-, 0.30-, 0.40-, 0.50-, 0.80- and 1-m depths. Periodically during the experiment, $\mathrm{MeBr}$ soil-gas samples were taken to a depth of $150 \mathrm{~cm}$.

Several methods were used to estimate the $\mathrm{MeBr}$ volatilization rate: the flux chamber (Denmead, 1979), aerodynamic (Parmele et al., 1972), theoretical profile shape (Wilson et al., 1982) and integrated horizontal flux methods (Denmead et al., 1977). For the micrometeorological methods, an air sampling mast was used to hold charcoal sampling tubes at heights of $0.1,0.2,0.5,0.8,1.2$ and $1.6 \mathrm{~m}$ above the field surface. These measurements provide the air concentrations and concentration gradients required to estimate the volatilization rate. Estimate of the cumulative emission were obtained by integrating the flux measurements and by calculating the difference between the applied mass and the $\mathrm{MeBr}$ mass degraded (e.g. $\mathrm{Br}^{-}$ion), several months after application. The cumulative emissions obtained from these methods varied from 58 to 70 per cent of the applied MeBr mass. A complete description of the experimental procedures is given in Yates et al. $(1996 \mathrm{a}, \mathrm{b}, \mathrm{c})$.

The purpose of this article is to determine the influence of the surface boundary condition on the pattern of pesticide emissions into the atmosphere and the ability of the model to simulate realistic emission rates by comparison to the field measurements of Yates et al. (1996b,c). A one-dimensional numerical model was developed to simulate $\mathrm{MeBr}$ degradation and movement in soil, and volatilization into the atmosphere. Since shank-injected soil fumigation results in a planar source of $\mathrm{MeBr}$ at the target depth, a one-dimensional model is appropriate for simulating the fate and transport process. Three volatilization boundary conditions, with increasing complexity, have been explored: (i) 
volatilization under isothermal conditions, (ii) volatilization in response to solar-driven temperature changes at the soil surface and (iii) volatilization from soil coupled to atmospheric processes.

\section{MODEL DESCRIPTION}

A numerical model was developed to simulate $\mathrm{MeBr}$ degradation and transport in soil and volatilization into the atmosphere. The model simultaneously solves partial differential equations for non-linear transport of water, heat and solute in a variably saturated porous medium.

The simulation of saturated-unsaturated water movement in soils is accomplished using the Richards equation

$$
C_{s}(\varphi) \frac{\partial \varphi}{\partial t}=\frac{\partial}{\partial z}\left[K(\varphi) \frac{\partial \varphi}{\partial z}\right]+\frac{\partial K(\varphi)}{\partial z}
$$

where $\varphi$ is the matric potential $(\mathrm{cm}), C_{s}(\varphi)$ is the specific moisture capacity $\left(\mathrm{cm}^{-1}\right), K(\varphi)$ is the unsaturated hydraulic conductivity $\left(\mathrm{cm} \mathrm{s}^{-1}\right), z$ is the depth coordinate $(\mathrm{cm})$ and $t$ is time (s). Since plastic film was present at the soil surface, a zero water flux boundary condition was used at the soil surface-atmosphere boundary.

The simulation of heat movement in soils is obtained using (Sophocleous, 1979)

$$
c_{v}(\theta) \frac{\partial T}{\partial t}=\frac{\partial}{\partial z}\left[\lambda(\theta) \frac{\partial T}{\partial z}\right]-c_{w} q \frac{\partial T}{\partial z}
$$

where $T$ is the soil temperature $(\mathrm{K})$ and $\lambda$ is the thermal conductivity $\left(\mathrm{W} \mathrm{m}^{-1} \mathrm{~K}^{-1}\right), q$ is the volumetric water flux density $\left(\mathrm{cm} \mathrm{s}^{-1}\right)$, and $c_{w}$ and $c_{v}$, respectively, are volumetric heat capacities for water and the porous medium at a water content, $\theta$. Since clear plastic film was present at the soil surface, significant solar heating occurred below the plastic. The surface boundary condition

$$
T_{o}(t)=\bar{T}+A \sin [\omega t+\Omega]
$$

was used to simulate the diurnal variation in the surface temperature, where $\bar{T}$ is the average daily temperature under the plastic, $A$ is the amplitude of the diurnal temperature variations, $\omega$ is the angular frequency and $\Omega$ is a phase lag to allow peak temperatures to differ from $1200 \mathrm{~h}$.

For a volatile organic chemical such as methyl bromide, the governing transport equation is

$$
\frac{\partial \theta C}{\partial t}+\frac{\partial \rho_{b} S}{\partial t}+\frac{\partial \eta G}{\partial t}=\frac{\partial}{\partial z}\left[D_{\ell} \frac{\partial C}{\partial z}+D_{G} \frac{\partial G}{\partial z}-q C\right]-\mu_{\ell} \theta C-\mu_{s} \rho_{b} S-\mu_{G} \eta G
$$

where $C, S, G$ are MeBr concentrations for the liquid, solid and gaseous phases, respectively $\left(\mathrm{g} \mathrm{cm}^{-3}\right)$; $D_{\ell}$ and $D_{G}$ are the liquid and vapor phase diffusion coefficients $\left(\mathrm{cm}^{2} \mathrm{~s}^{-1}\right)$, respectively, $\mu$ is a firstorder degradation coefficient $\left(\mathrm{s}^{-1}\right)$ and $\theta, \rho_{\mathrm{b}}, \eta$, respectively, are the water content $\left(\mathrm{cm}^{3} \mathrm{~cm}^{-3}\right)$, bulk density $\left(\mathrm{g} \mathrm{cm}^{-3}\right)$ and the air content $\left(\mathrm{cm}^{3} \mathrm{~cm}^{-3}\right)$. The subscripts $\ell, s$ and $G$ indicate liquid, solid and gaseous phases, respectively. The model allows both liquid and vapor diffusion and assumes that volatile solutes are partitioned between the liquid and gas phases following Henry's Law. Soil 
degradation is simulated using a first-order decay reaction and the rate constants can differ in each of the three phases (i.e. liquid, solid or gaseous). A soil-atmosphere boundary condition is

$$
-\left.D_{E} \frac{\partial C}{\partial z}\right|_{z=0}+\left.q C\right|_{z=0}=-\left.h\left(G-G_{a i r}\right)\right|_{z=0}
$$

where $h$ is a mass transfer coefficient $\left(\mathrm{cm} \mathrm{s}^{-1}\right)$ across a stagnant boundary layer, $G_{\text {air }}$ is the gas concentration on the atmosphere side of the boundary layer, and $D_{\mathrm{E}}=D_{\ell}+K_{\mathrm{H}} D_{\mathrm{G}}$ is the effective dispersion coefficient. The mass transfer coefficient is often related to the air diffusion coefficient by (Jury et al., 1983)

$$
h=\frac{D_{G}^{a i r}}{b}
$$

where $b(\mathrm{~cm})$ is the stagnant boundary layer thickness. The thickness of this layer controls vapor transport away from the soil surface. In Equation 6 the boundary layer thickness, $b$, embodies all of the processes that affect the transport of a chemical across the soil-atmosphere interface. However, when plastic covers the soil, there are additional diffusive terms that can affect gas movement from the soil to the atmosphere. These include diffusion beneath the plastic film, diffusion through the film, diffusion in the atmosphere near the film surface and turbulent transport to the measurement height.

By comparing the various diffusive terms, Wang et al. (1997) found that the plastic material dominated the transport. The simulation algorithm they used included only one varying parameter, i.e. $b$ in Equation 6, and therefore only the dominating diffusive process could be included into their simulation. To include the other resistance terms requires a more complex approach for estimating the mass transfer coefficient or a more flexible simulation algorithm.

An alternative formulation for the mass-transfer coefficient that includes atmospheric resistance terms is (Baker et al., 1996)

$$
h=\frac{u^{*}}{7.3 R_{e}^{1 / 4} S_{c}^{1 / 2}+\left(\frac{U_{r}}{u^{*}}-5\right) \Phi_{m}}
$$

where $R_{e}$ and $S_{c}$, respectively, are the roughness Reynolds and Schmidt numbers, $u^{*}$ is the friction velocity $\left(\mathrm{cm} \mathrm{s}^{-1}\right), U_{r}$ is the wind speed at the measurement height $\left(\mathrm{cm} \mathrm{s}^{-1}\right)$ and $\Phi_{m}$ is an atmospheric stability correction. The denominator of Equation 7 consists of two atmospheric resistance terms: one representing diffusive resistance near the soil surface and the other aerodynamic resistance from the diffusive layer to the measurement height. To use Equation 7, meteorological measurements are needed including gradients of wind speed and temperature.

Three simulations were conducted. Two of the simulations used Equation 6 for the volatilization boundary condition, one for isothermal conditions ( $b$ constant) and the other for solar-induced, temperature-dependent conditions, where

$$
b=b_{o} e^{\frac{E_{a}\left(T-T_{o}\right)}{R T T_{o}}}
$$

and $E_{a}$ is the activation energy $(\mathrm{J} / \mathrm{mol}), R$ is the universal gas constant $(8.314 \mathrm{~J} / \mathrm{mol}-\mathrm{K}), b_{o}$ is the boundary layer thickness at the reference temperature $T_{o}$, and the temperatures in Equation 8 are in 


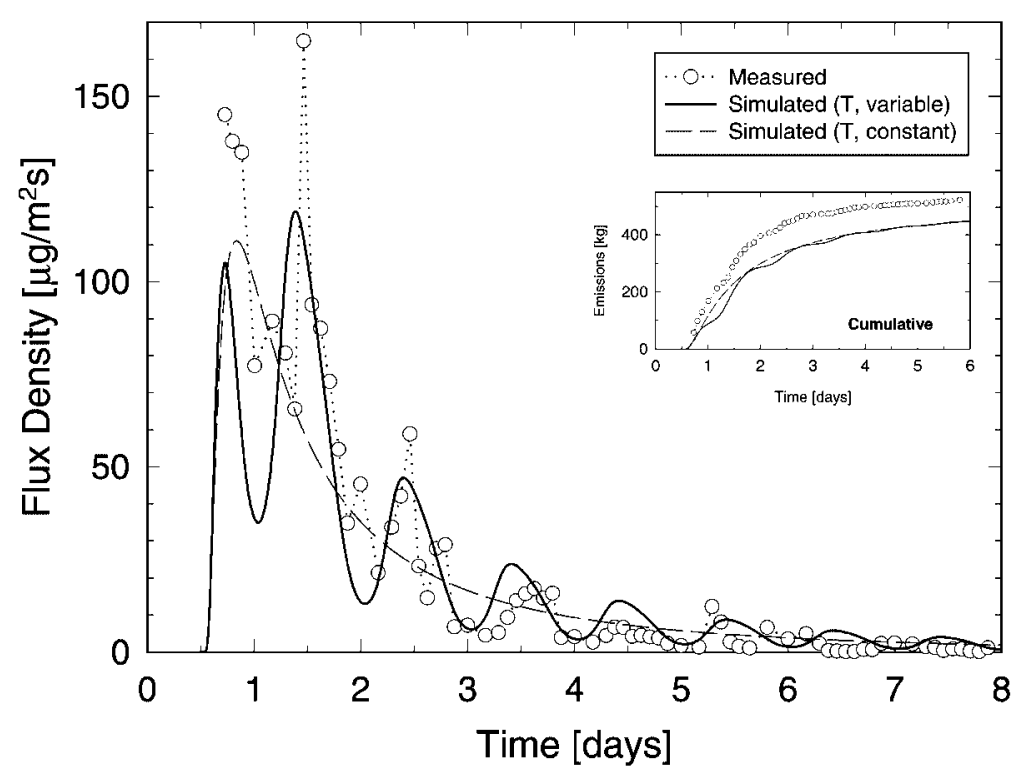

Figure 1. Volatilization of $\mathrm{MeBr}$ as a function of time. Open circles are measured volatilization rates and solid (variable temperature) and dashed lines (constant temperature) are simulated values. The inset shows cumulative emissions

Kelvin. The third simulation used Equation 7 and was coupled to measured micrometeorological conditions. All simulations were conducted in a predictive mode with the parameters determined from independent measurements.

\section{RESULTS}

Figure 1 shows a comparison of measured and simulated volatilization rates assuming isothermal conditions (dashed line) and diurnal temperature variations (solid line). The measured values (circles) were obtained by averaging the volatilization estimates from four methods: chamber, aerodynamic, integrated horizontal flux and theoretical profile shape methods. For both simulations, the cumulative emission (see inset) was approximately 55 per cent of the applied $\mathrm{MeBr}$ after 8 days. The cumulative emissions obtained from the average of the measured volatilization rates were 64 per cent, although the individual cumulative emissions ranged from 58 per cent (chamber method) to 70 per cent (integrated horizontal flux method).

If isothermal conditions are assumed, the model can be considerably simplified by noting that the tarp effectively halts surface evaporation, and therefore water movement in the soil is minimal. This allows Equations 1 and 2 to be neglected, and Equation 4 can be simplified so that a solution can be obtained in analytic form (i.e. see Jury et al., 1983). It is noteworthy that when the appropriate average temperature is used to calculate the transport parameters (i.e. $h$ is determined using the average temperature under the tarp), the predicted cumulative emissions are the same as the more complex numerical model. This indicates that simple solutions may provide important information concerning the transport process - in this case, the cumulative emissions. This result may also be valid for other information that is integrated over relatively long time periods. 


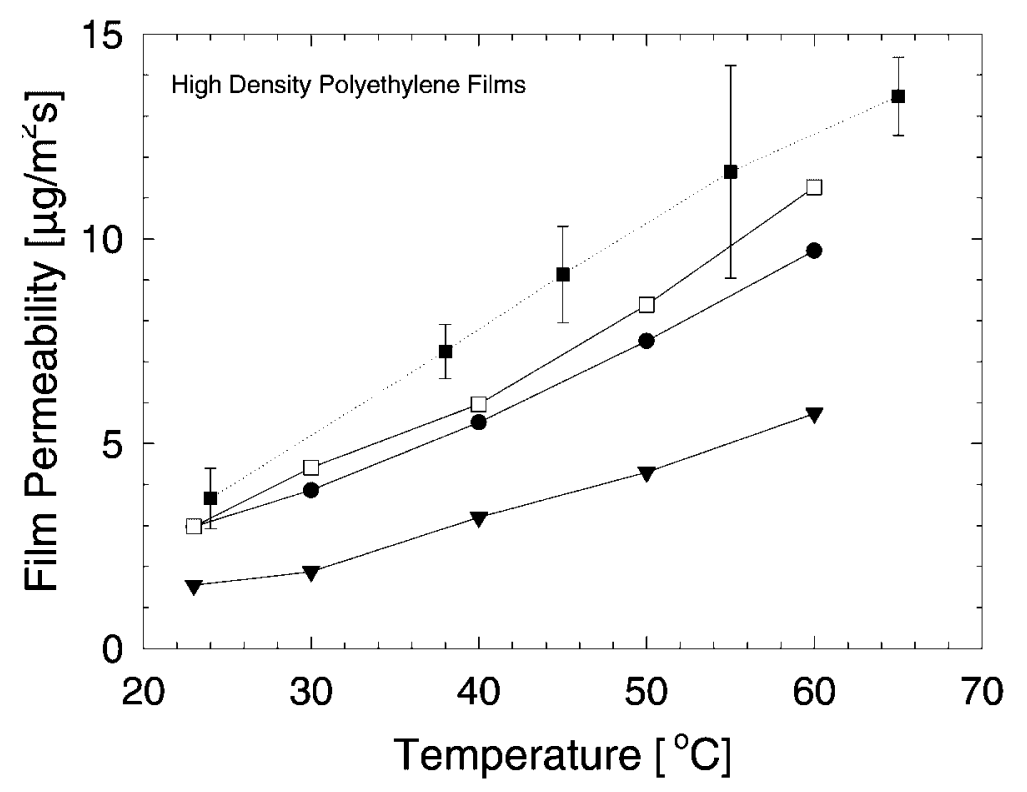

Figure 2. Permeability of several high-density polyethylene (HDPE) films as a function of ambient temperature. These films are typically used in soil fumigation. A $10^{\circ} \mathrm{C}$ increase in temperature corresponds to a 50-100\% increase in permeability. Data are unpublished [ $\mathbf{\square}]$ and from Kolbezen and Abu-El-Haj (1977)

Although simple models may provide certain useful information, they are inappropriate for estimating the instantaneous volatilization rate (Figure 1) under field conditions, since many other processes affect the instantaneous rate (i.e. temperature, atmospheric stability, etc.). For example, high-density polyethylene film plays an important part in controlling $\mathrm{MeBr}$ emissions to the atmosphere since it is highly permeable to MeBr (Kolbezen and Abu-El-Haj, 1977; Papiernik et al., 2001). This is demonstrated in Figure 2, where the effect of temperature on film permeability is shown. For this film, a $10^{\circ} \mathrm{C}$ increase in temperature produces a 50-100 per cent increase in the permeability rate of high density polyethylene. Experimental measurements of the air temperature below the plastic film ranged from $16^{\circ} \mathrm{C}$ to $61^{\circ} \mathrm{C}$ during the first few days of the experiment. This translates into a 5- to 10 -fold change in film permeability, which has a dramatic effect on the field volatilization rate. The high permeability also contributes to the rapid decrease in maximum daily emission rate over the course of the experiment. Each day, large amounts of $\mathrm{MeBr}$ were lost to the atmosphere (36 and 18 per cent during the first two days following application), reducing the concentration gradient between the soil surface and atmosphere. Large $\mathrm{MeBr}$ losses also affect pest control and often require higher application rates to compensate.

To simulate the effect of temperature-induced changes in film permeability on the $\mathrm{MeBr}$ volatilization rate, the volatilization boundary condition must be coupled to surface temperature. Surface heating is directly related to incoming solar radiation, and therefore the volatilization rate follows a diurnal cycle. Since there was no significant cloud cover during the experiment, the cyclic pattern of surface heating is very smooth (Figure 3).

The smooth nature of the simulated volatilization rate (Figure 1) is a consequence of the smooth surface-temperature input function. For this case, the volatilization rate is controlled by the film 


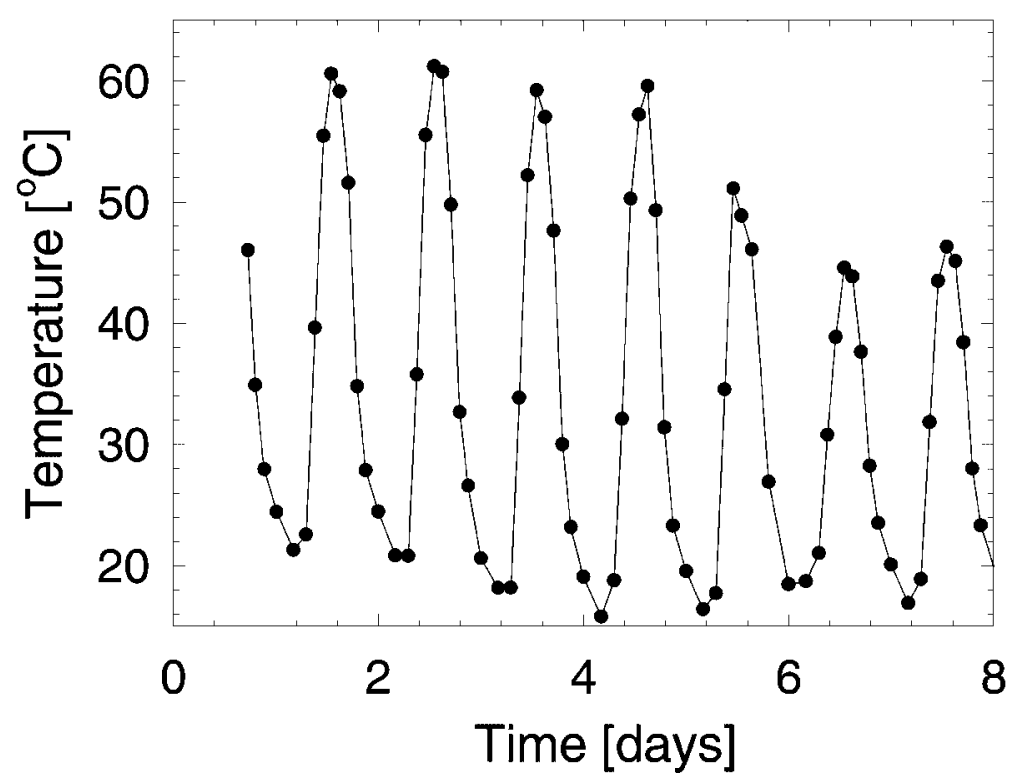

Figure 3. Air temperature $\left({ }^{\circ} \mathrm{C}\right)$ measured under the tarp

permeability through the boundary layer thickness parameter (Equations (6) and (8), where $b$ changes with temperature and yields a varying $h$ ). Since there is a loss of chemical through the tarp with time, the cyclic nature of the volatilization rate decays, unlike the temperature under the tarp. However, the averaged measured volatilization rates are not nearly as smooth as the simulated values. Many other processes affect the instantaneous volatilization rate, such as the atmospheric stability, turbulent mixing and spatial variability of the plastic permeability, among others.

The erratic nature of the actual volatilization rate is important for the protection of public and environmental health. During these periods of intense emissions, persons or wildlife near a treated field may be exposed to large quantities of toxic material and may require extra regulatory protection. On the other hand, it is also important to determine if these high volatilization rates are artifacts of the data, since regulations based on such data would be unnecessarily restrictive. Therefore, accurate simulation of peak emission rates is desirable. This cannot be accomplished using soil-based information alone. Since it is known that the volatilization rate depends on both soil and atmospheric conditions, an appropriate mass transfer coefficient should couple soil and atmospheric processes.

Figure 4 shows the predicted $\mathrm{MeBr}$ emissions when Equation 7 is used to obtain the mass transfer coefficient. It is clear that atmospheric conditions affect the volatilization rate, since the smooth sinusoidal behavior has been replaced with more erratic cycles. At many sample times, the predicted rates more closely match the measured values, especially at 1.5 and 2.5 days. During these mid-day periods, the atmosphere is thermally unstable, which enhances the rate of volatilization. Assuming that the tarp permeability is the sole controller of emissions caused an underestimation of the emission rate at these critical times. Coupling the mass transfer coefficient to atmospheric processes produced more accurate emission predictions of these peak values. At later times, however, the simulation over-predicted the daily peak emission. The large discrepancy at $5 \frac{1}{2} d$ is due to the removal of the 


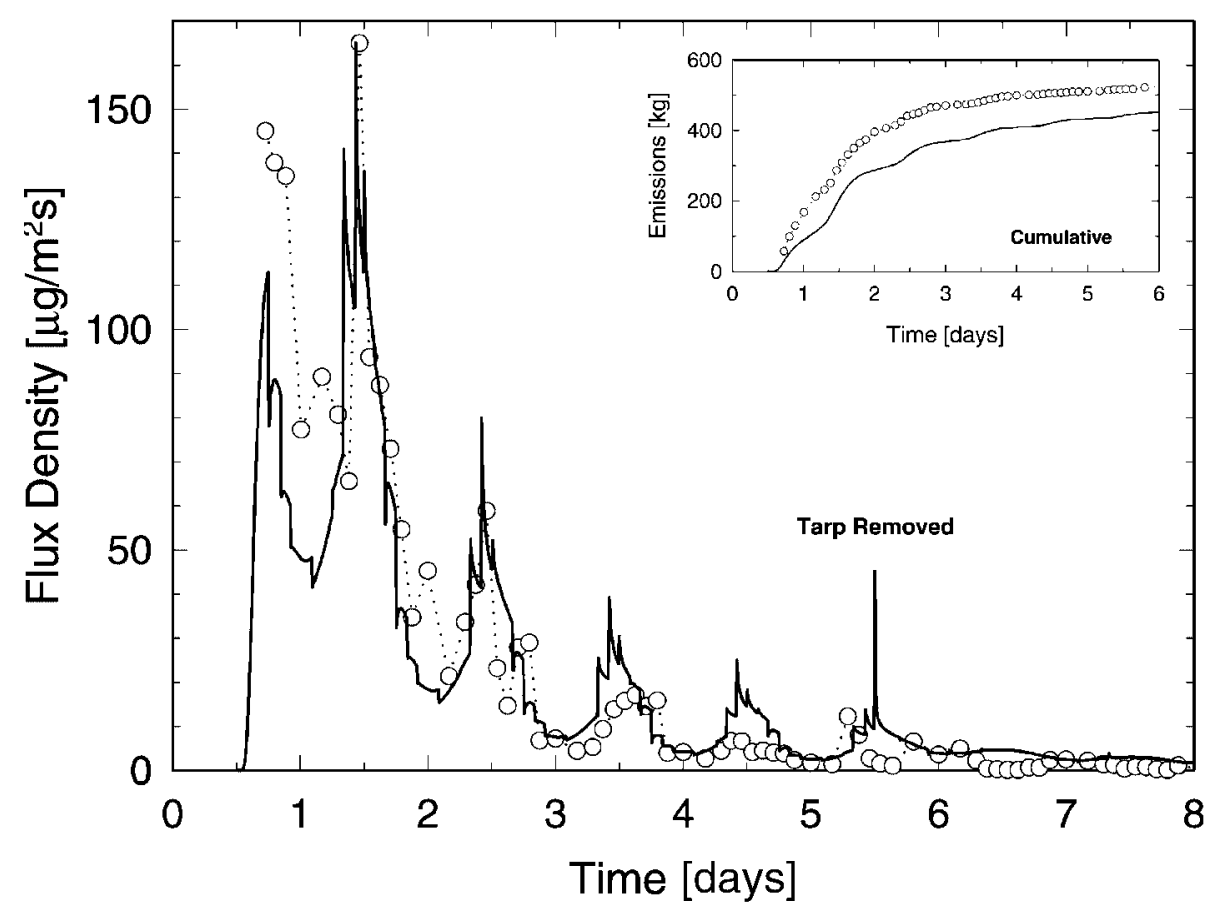

Figure 4. Volatilization of $\mathrm{MeBr}$ as a function of time. Open circles $(\mathrm{O})$ are measured volatilization rates obtained by averaging the estimates from four methods: chamber, aerodynamic, integrated horizontal flux and theoretical shape. The solid line (-) is the simulated volatilization rate using Equation (7) to describe the surface volatilization boundary condition. The inset shows the measured $(O)$ and simulated (-) cumulative emissions. The tarp was removed at 5.5 days

plastic from the field. In the simulation, the plastic was removed instantaneously; in the field this took several hours.

The predicted volatilization rate shown in Figure 4 closely matches the average measured volatilization rate. However, there is no indication that the average of the measured volatilization rates is the preferred measure of the accuracy of the approach. Of the various methods for measuring the volatilization rate, each produces different emission histories, as is shown in Figure 5 for the chamber method and the integrated horizontal flux methods. These methods produced the lowest and highest cumulative emissions (i.e. 58 and 70 per cent).

The volatilization rate appears to be more erratic for a particular method compared to the average rate shown in Figure 1. For both the chamber and integrated horizontal flux methods, the simulated volatilization rate provides reasonable predictions. For the integrated horizontal flux method, the first three values were much higher than the estimates from the other methods, which suggests that these may be artifacts. Replacing these values with those obtained from the average causes the cumulative emissions to be approximately the same as the simulation (Figure 4).

Although model calibration would improve the match between simulated and measured volatilization rate, calibration would not provide a test of the predictive capability of the models and boundary conditions. Based on the information presented, a volatilization boundary condition that is coupled to soil and atmospheric processes provides a more accurate description of the emission process and should be used when instantaneous volatilization rates are required. 

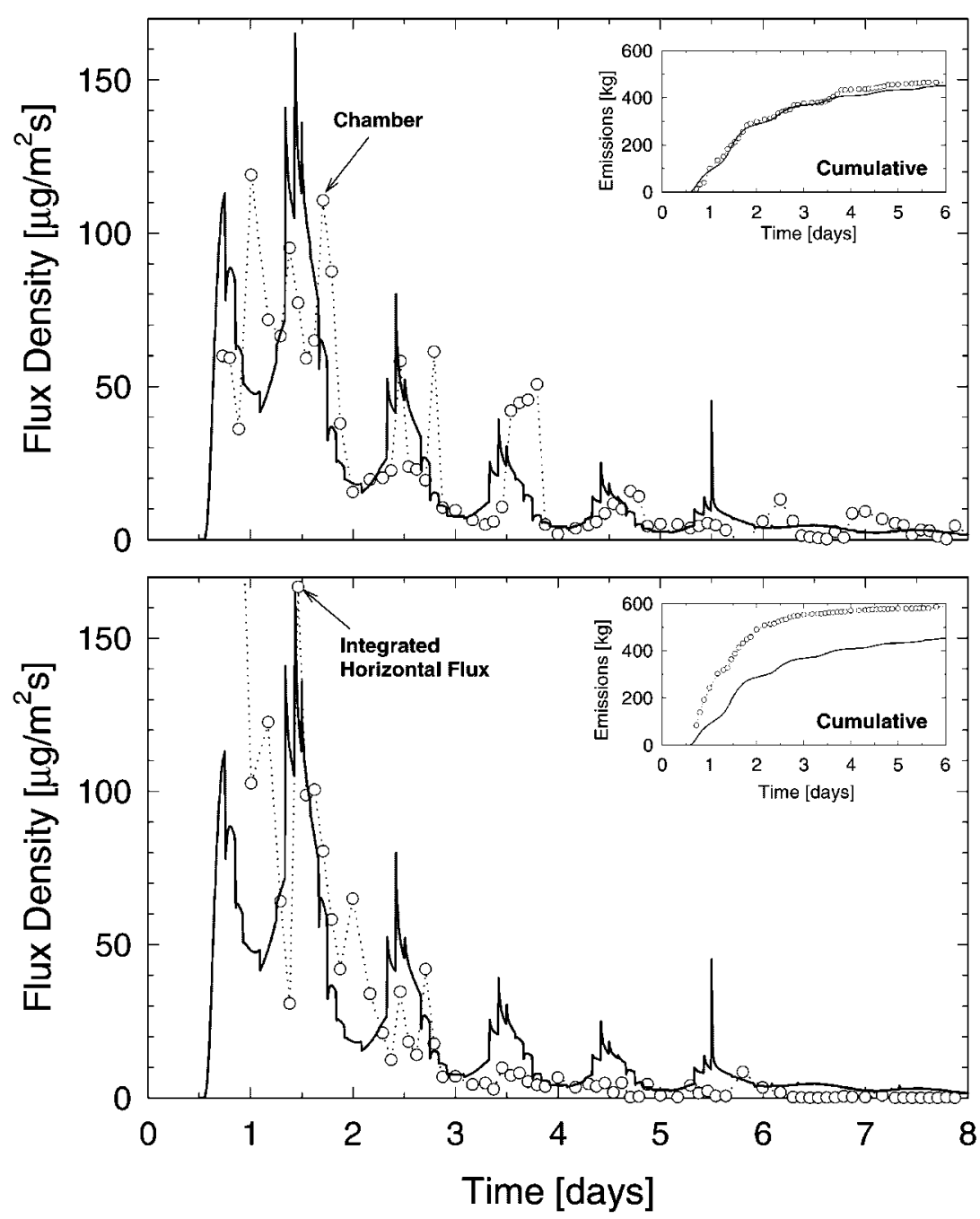

B

Figure 5. Volatilization of $\mathrm{MeBr}$ as a function of time. In (A), open circles (O) are measured volatilization rates from flux chamber. In (B), open circles $(\bigcirc)$ are measured volatilization rates from the integrated horizontal flux method. In both $(\mathbf{A})$ and (B), solid lines (-) are simulated values using the boundary condition in Equation (7). The insets shows the measured (O) and simulated (-) cumulative emissions

\section{REFERENCES}

Baker JM, Koskinen WC, Dowdy RH. 1996. Volatilization of EPTC: simulation and measurement. Journal Environmental Quality 25: 169-177.

Denmead OT. 1979. Chamber systems for measuring nitrous oxide emission from soil in the field. Soil Science Society of America Journal 43: 89-95.

Denmead OT, Simpson JR, Freney JR. 1977. A direct field measurement of ammonia emission after injection of anhydrous ammonia. Soil Science Society of America Journal 41: 1001-1004.

Ferguson W, Padula A. 1994. Economic effects of banning methyl bromide for soil fumigation. Agricultural Economic Report 677. 
Jury WA, Spencer WF, Farmer WJ. 1983. Behavior assessment model for trace organics in soil: 1. Model description. Journal Environmental Quality 12: 558-564.

Kolbezen MJ, Abu-El-Haj FJ. 1977. Permeability of plastic films to fumigants. Proc. International Agricultural Plastics Congress. San Diego, California, 11-16 April 1977; 6 pp.

Majewski MS, McChesney MM, Woodrow JE, Pruger JH, Seiber JN. 1995. Aerodynamic measurements of methyl bromide volatilization from tarped and nontarped fields. Journal Environmental Quality 24: 742-752.

Mano S, Andreae MO. 1994. Emission of methyl bromide from biomass burning. Science 263: 1255-1257.

NAPIAP. 1993. The biologic and economic assessment of methyl bromide. United States Department of Agriculture, National Agricultural Pesticide Impact Assessment Program. Washington, DC, April 1993; 99 pp.

Papiernik SK, Yates SR, Gan J. 2001. An approach for estimating the permeability of agricultural films. Environmental Science and Technology 35: 1240-1246.

Parmele LH, Lemon ER, Taylor AW. 1972. Micrometeorological measurement of pesticide vapor flux from bare soil and corn under field conditions. Water, Air, Soil Pollution 1: 433-451.

Sophocleous M. 1979. Analysis of water and heat flow in unsaturated-saturated porous media. Water Resources Research 15: 1195-1206.

Wang D, Yates SR, Gan J. 1997. Temperature effect of fate and transport of methyl bromide in soil fumigation. Journal Environmental Quality 26: 1072-1079.

Watson RT, Albritton DL, Anderson SO, Lee-Bapty S. 1992. Methyl Bromide: Its Atmospheric Science, Technology, and Economics. United Nations Environment Programme (UNEP), United Nations Headquarters, Ozone Secretariat, PO Box 30552, Nairobi: Kenya.

Williams J, Wang NY, Cicerone RJ. 1999. Methyl bromide emissions from agricultural field fumigations in California. Journal Geophysical Research-Atmospheres 104: 30087-30096.

Wilson JD, Thurtell GW, Kidd GE, Beauchamp EG. 1982. Estimation of the rate of gaseous mass transfer from a surface source plot to the atmosphere. Atmospheric Environment 16: 1861-1867.

Yagi K, Williams J, Wang NY, Cicerone RJ. 1993. Agricultural soil fumigation as a source of atmospheric methyl bromide. Proceedings of the National Academy of Sciences of the United States of America 90: 8420-8423.

Yagi K, Williams J, Wang NY, Cicerone RJ. 1995. Atmospheric methyl bromide $\left(\mathrm{CH}_{3} \mathrm{Br}\right)$ from agricultural soil fumigations. Science 267: 1979-1981.

Yates SR, Gan J, Ernst FF, Mutziger A, Yates MV. 1996a. Methyl bromide emissions from a covered field. I. Experimental conditions and degradation in soil. Journal Environmental Quality 25: 184-192.

Yates SR, Ernst FF, Gan J, Gao F, Yates MV. 1996b. Methyl bromide emissions from a covered field. II. Volatilization. Journal Environmental Quality 25: 192-202.

Yates SR, Gan J, Ernst FF. 1996c. Methyl bromide emissions from a covered field. III. Correcting chamber flux for temperature. Journal Environmental Quality 25: 892-898.

Yvon-Lewis SA, Butler J. 1997. The potential effect of oceanic biological degradation on the lifetime of atmospheric $\mathrm{CH}_{3} \mathrm{Br}$. Geophysical Research Letters 24: 1227-1230. 